\title{
Network Capital: an Expression of Social Capital in the Network Society
}

\author{
Manuel Acevedo \\ Independent Consultant; Ph.D. Candidate, Open University of Catalonia \\ $<$ manuel@manuelacevedo.net>
}

\begin{abstract}
This article deals with an emerging type of social capital which is labeled as 'network capital'. It is formed from collaborative practices emerging from e-enabled human networks. It is proposed that network capital is a specific type of social capital in the Network Society, and that it holds significant value for the advancement of human development around the world.
\end{abstract}

\section{Social Capital and Human Development}

According to Amartya Sen, 'human development' refers to the expansion of choices (i.e. freedoms) for people to live better lives. This concept has universal application, so it is not only valid for under-developed nations (the global 'South'). Many factors play into human development, among them the inclusiveness of a society.

There is mounting evidence showing that social cohesion is critical for advancing human development. Participation, trust, solidarity and reciprocity, grounded in a shared understanding and a sense of common obligations, are mutually reinforcing values at the heart of good governance and proper citizenship.

The challenge resides in characterizing and measuring the effects and impacts of social cohesion. Robert Putnam, in his landmark 1993 book "Making Democracy Work" started to provide some empirical evidence for what is now called 'social capital' when he examined development levels in different parts of Italy. He concluded that variances in performance among different parts of the country could be largely accounted for in terms of social capital, characterized by participation in voluntary associations, or "horizontal networks of civic engagement".

Social capital is a measure of social cohesion, and one of the indicators of the overall 'wealth' of a country/society (together with financial, human, natural and physical capitals). The World Bank defines it as "the institutions, relationships, and norms that shape the quality and quantity of a society's social interactions. (...). Social capital is not just the sum of the institutions which underpin a society - it is the glue that holds them together."

Another definition for social capital, this time in relation to networks, is as "the networks of social interaction and the norms of reciprocity that allow the individual and the community to assume a habit of civic collaboration aimed at common goals" [UNV 2000]. This definition has the double advantage of treating social capital as a network concept and it introduces the fundamental element of 'commonality' which puts it in the sphere of public goods.

We can thus appreciate the inherent policy dimensions of this new indicator of wealth: "The networks of social capital that exist below the waterline of public visibility are an indispensable component of any strategy aimed at promoting social integration, poverty reduction and sustainable development" [UNV 2000]. Governments and other governance actors will be wise to consider ways to promote and invest in social capital because it is a cost-effective asset for human development processes. And it comes with positive externalities like the decentralization of initiative-taking and the spreading of responsibilities in a more democratic and participatory governance structure.

\section{Social capital in the Network Society: towards the notion of "network capital"}

People have a timeless tradition of cooperating to achieve common results. There may be something genetic in our ability to pool together for common goals, as well as in being shaken by others' suffering. Despite issues of competition (sometimes taken to appallingly cruel extremes), persons have been helping other persons (beyond family or professional contexts) throughout history.

It is relevant to discuss social capital in the new context given by the emergence of a new phase of history, the Information Age, and its functional structure, the Network Society. Wellman writes that "the transformation of national and global societies into 'network societies' suggests the usefulness of thinking of social capital as a product of personal community networks as well as of formally institutionalized groups." It is well beyond the scope of this article to try to explore social capital in this new social context. Rather, our focus here is merely one aspect of it, which can be named 'network capital'. 
Communities are no longer defined only by place, but also by interest, becoming organized into social networks. When the interaction takes place among members of an electronic network, which are likely loosely-knit in geographic terms, the resulting social capital is network based. Network capital could then be understood as a measure of the differentiated value in the Information Age that communities structured as social networks generate on the basis of electronic (digital) networks for themselves, for others and for society as a whole.

In this context, network capital can become a valuable asset for human development for two main reasons. First, because of the earlier mentioned importance of social capital for human development - and network capital being but one expression of social capital in the Information Age. Second, because development cooperation is meant to be an accelerator of human development processes, and the generation and investment of network capital has the potential to significantly contribute to renewed models of development cooperation in the Network Society.

There is insufficient treatment of this particular aspect of social capital in the literature, perhaps because it is only very recently with the meteoric rise of the Web 2.0 phenomenon that it is approaching enough of a critical mass to make a difference. Wellman describes network capital as the form of social capital that makes resources available through interpersonal ties. He writes that it consists of "knowing how to maintain a networked computer, search for information on the Internet and use the knowledge gained, create and sustain online relationships, and use these relationships to obtain needed resources, including indirect links to friends of friends." [Wellman 2001] and that it can be measured by "the frequency of social contact with friends, relatives, and workmates." While these are indeed elements of network capital, they clearly do not sufficiently explain it.

Community Informatics (CI) is a field that draws closer to the idea of network capital. Simpson [2005] refers to social capital constructed via CI, clearly making use of ICTs but not entirely due to ICTs and e-networks. CI-generated social capital indeed has some elements of network capital (see listing ahead) - we could say it is 'ICT-aided' social capital. Network capital, on the other hand, is 'ICT-enabled' social capital [Van Bavel et. al. 2004], admittedly an elastic differentiation and one to further explore. However, this difference is one that points at social capital created almost exclusively through electronic networks, plus it is not bound by physical location as often occurs in CI. In Castells' terms, network capital is the social capital of the 'space of flows'.

While it is arguable that the accelerated emergence of Web 2.0 applications may radically transform the use of the Internet over the next 10-15 yrs., it has undoubtedly already provided the necessary e-tools for communities that form social networks to elevate their interaction by quantum leaps. There are 2.0 tools for weaving social networks (personal or professional), to support collaboration (wikis, content aggregators, groupware, mapping, tagging) or to simply facilitate content sharing (videos, photos, RSS feeds, podcasting or the ubiquitous blogs). These are being used in waves by a generation that grew up with video games and PCs, at such a scale where it may soon deliver significant effects, in social as well as economic terms.

This massive and current instance of technological social absorption provides a powerful added stimulus to advance the analysis of network capital, so we can better understand the nature of interaction, trust and collaboration over the new global digital environment. Such improved understanding will serve various purposes, whether in promoting its positive outcomes (e.g. to defend human rights or to provide income-generation opportunities) or in preventing/correcting pernicious consequences (such as criminal activities or the spread of intolerant social values).

Network capital can be characterized through a combination of attributes, only some of which may normally be manifested concurrently in a given community:

- It is a result of cooperation via electronic networks, and in turn fosters the habit of such cooperation. This cooperation includes sharing of information and the use of computer-mediated-communications but it goes further towards group work, the creation of specific products, and the achievement of set objectives.

- It is largely produced by volunteer action and contributions (though not exclusively, as it can be operationalized within organizations like companies).

- It is created by communities of interest, where membership is based on personal interest, skills, background/experience and sharing of a common purpose. While network technologies allow for anyone in the world with Internet access to take part (in fact many virtual communities are geographically dispersed), physical proximity may be a factor as well, as evidence from local community/citizen networks, as Gurstein [2000] has shown.

- It is generated by people organized as a virtual community who share a communal cyberplace as for example through a simple e-discussion list, a suite of groupware applications, or a sophisticated 2.0 virtual environment like Second Life.

- It is largely produced from asynchronous communications which provide greater flexibility for the human nodes of the networks and allow them to take advantage of the 'timeless time' (ie. asynchronous) features of the Network Society [Castells 1998].

- It has been particularly concerned with knowledge generation, and thus adds a special value to knowledge- 
intensive processes (such as those related to scientific, R\&D, policy-making or development cooperation).

- It favors the expanded participation of people in matters of common interest, by facilitating the logistics and dynamics of such involvement. It thus opens up a wider array of possibilities for individuals to behave as 'global citizens', and to become involved in actions and issues not bounded by their physical location.

An early and still paradigmatic example of network capital comes from the creation of Free/Open Source software (FOSS). People from different locations, who may not ever see each other, use Internet and net-based tools to exchange information, generate knowledge, work collaboratively and develop well-defined products, 'all for the love of it'. These people consider themselves as software artists (even activists), and participate on a voluntary basis. They meet at specific cyberplaces, eg. distribution lists, extranets or project management applications, and sometimes in person as well, at conferences or other public events.

FOSS communities have crafted a culture of sharing and solidarity which not only makes their processes sustainable, but is a stimulus and reference for others to also pursue electronic-based collaboration. The 'Open-Source' approach is becoming known for its methods and philosophy in fields outside of software production, as a collaborative methodology. This collaboration helps the individuals who take part in it, and the resulting products help specific personal or institutional users, as well as large sectors of society who in this way have additional software choices made available to them - a good example of knowledge as a global public good. FOSS programs such as GNU/Linux, Apache, Perl, Firefox, OpenOffice, MySQL or PHP have all become intrinsic parts of the digital environment.

Let us now illustrate some possibilities for the generation and usefulness of network capital in development cooperation, by looking at one of its most basic elements, the development project.

\section{Putting Network Capital in action: re-architecting the development project as a network}

Let us take the traditional 'development project' (ie. in health, education, employment, environment, etc.) in countries in the South as an item/model which can change significantly through the generation of network capital. Traditionally, a development project is defined by a set of objectives or expected outcomes, a given timetable, a budget, an array of inputs and some methodologies. It involves staff, local counterparts, the sponsoring agency, and often some short-term outside 'expert' assistance.

In the context of the Network Society, development projects can be seen in a new light as 'network entities'. The project network would be part of the architecture and processes of the project, where a number of networked nodes with well-defined individual and collaborative tasks provide the inputs and resources to achieve the project's objectives. Benefiting from the Internet, neither distance nor time constraints irrevocably limit the involvement of a significantly wider group of participants, many of whom may undertake this participation as volunteers. This innovative approach of 'the-project-as-a-network' can increase the engagement of people and institutions by orders of magnitude, and provide more opportunities of involvement of the 'global citizen'.

Figure 1 illustrates a collaborative network which can be set up for a development project. The diagram shows the types of institutions and individuals that can become involved (whether formally or informally). The diagram is not meant to illustrate an entire project network; that would require the inclusion of additional inter-relations and participants (e.g. project staff, implementing organizations, donor agency).

Most of the relationships identified below would be of a voluntary nature - e.g. collaboration between peers in development agencies working on similar topics. In the graph, while the examples of secondary or indirect collaborations are hinted at, the possibilities are more extensive and would make for a convoluted graphic representation.

The types of involvement are outlined as follows: 


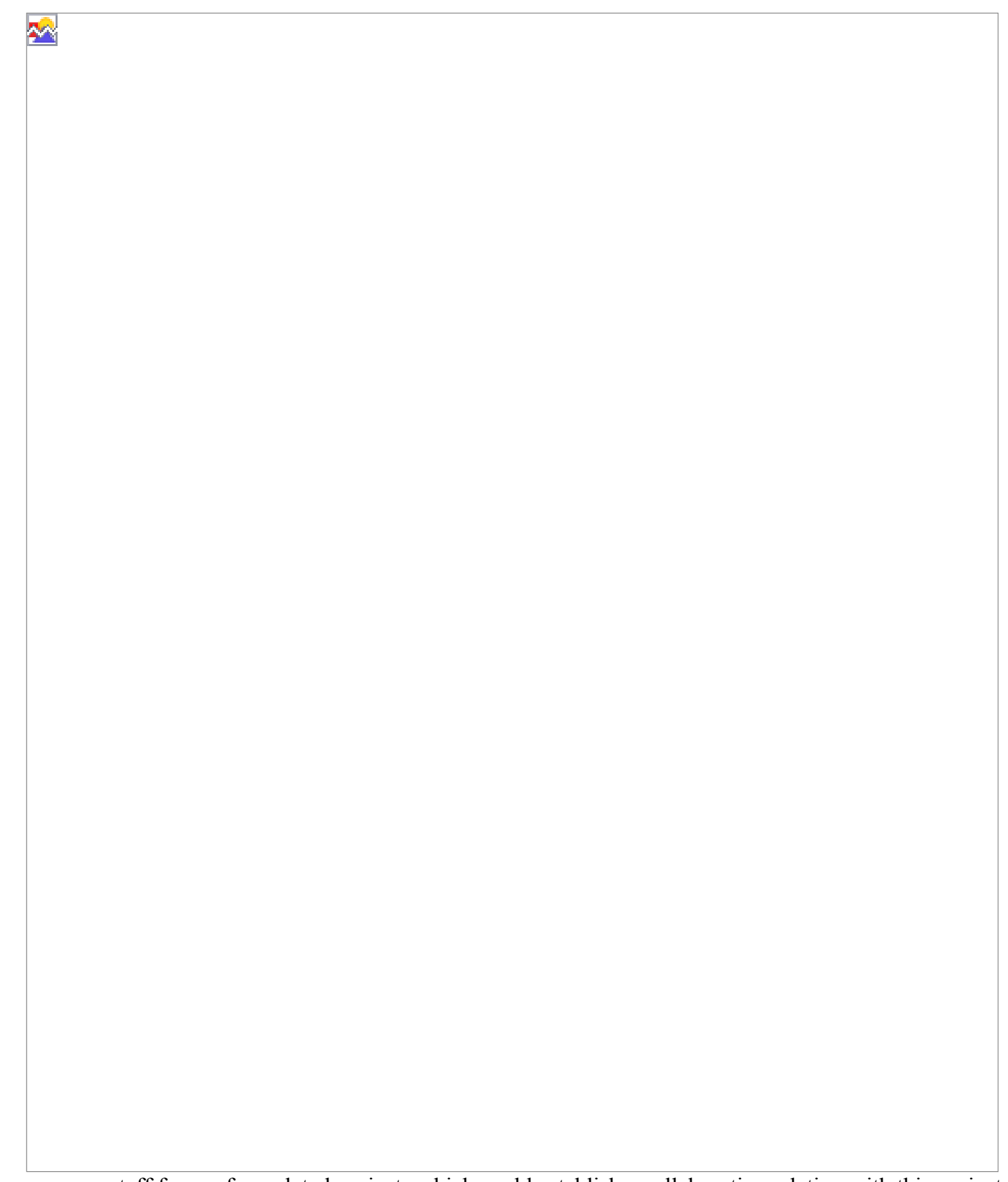

- $\quad$ staff from a few related projects which could establish a collaborative relation with this project;

- members of some NGOs with thematic expertise or other direct interest in the issues dealt with by the project;

- online volunteers performing activities tasked to them by project staff;

- onsite volunteers supporting the project;

- companies interested in the project topic, possibly under their corporate social responsibility (CSR) area of activity;

- individuals participating in a virtual community of practice linked with the project thematic area;

- students and professors of a university that are studying and researching the issues dealt with by the project ; and

- $\quad$ staff from a different development agency than the one supporting the project.

Network capital would emerge from this approach in various ways. Adequate network dynamics and tools would be needed for a relatively large number of individuals and institutions to become involved in an effective and efficient fashion. This human network within the larger project (and largely virtual) community would only coalesce for the purposes of the project, because it would be created and tailor-made for that purpose. The collaborative working methods are sure to resonate with some of the people involved, who would apply them later in other spheres. Some of the relationships initiated by the projects would become lasting human bonds, either for professional or personal 
purposes. The results and outcomes of the project would arguably prove to be, to a significant extent, a consequence of the network capital formed during its implementation.

Some considerations that emerge when examining this networked approach to project implementation:

a. The role of a 'project network architect' as part of the project staff would be recommended. The design, construction, 'caring' maintenance and motivation of such a network will not happen in an ad-hoc fashion and will take considerable effort and dedication.

b. Variable network geometries with different configurations and densities can be established, with an essentially infinite set of combinations. Any given project can set up a tailor-made collaborative network.

c. The project would need to be designed with network structures permeating its formulation, strategy, methodology, institutional arrangements, and monitoring \& evaluation.

d. Participation by individuals through this type of project architecture diminishes the exposure to the "network fatigue syndrome', since tasks would be specific and time-bound, and collaboration would not be open-ended and ad-hoc.

\section{Further Research for network capital}

Much more research is required to clarify and characterize both the concept and the methods of network capital as well as for this research to proceed alongside the developments with respect to social capital and its evolution in the context of the Network Society. Some of the lines on which purposeful research could be conducted are would be in relation to:

- Methodologies of measuring network capital based on diverse interpretations of the concept, and comparative analysis of the presumably diverse results.

- Quantitative and qualitative differences among actions of groups/communities that have absorbed the use of the Internet and other ICTs (in issues like gender equity, human rights, environmental protection, etc.), in comparison with others whose ICT use is markedly lower. Analyzing the differences also in terms of results and the impacts of those actions?

- Differences between geographic zones with differing levels of social capital and integration in the Network Society, controlling for socio-economic factors and calculation methods.

- Comparison between results emerging from social action oriented towards the generation of public goods based on 'weak links' vs. 'strong links' (in reference to Wellman's work).

- Characterization of 'social cohesion' and what quantitative/qualitative indicators are more suitable for its analysis. Relations between social cohesion and weak/strong links.

- Results of political actions and decisions aimed at promoting the creation of social capital and network capital in diverse geographical areas.

\section{Conclusion}

The emergence of the Information Age brings about a related new paradigm in the form of the Network Society. Social capital, which acts as a glue that keeps societies together, will have new manifestations in such an environment. One of these which was labeled 'network capital' in this article, is characterized by the distributed methods and electronic technologies which are inherent to networked operations in our days. Network capital is 'ICT-enabled' and will be a measure of how people collaborate through electronic networks for personal, communal and even global benefits. In other words, it is the social capital of the 'space of flows' described by Castells.

The Open Source movement provides an excellent example of network capital. Software programmers, organized through virtual communities of practice, are creating both important network value (good software products) as well as values (the principles and the practice of tight collaboration on a specific technical area).

Network capital holds important potential for human development and specifically for development cooperation, where global and local issues mix fluidly in the processes leading to greater options for people and improved living conditions. The global citizen will have more possibilities to become involved in social causes, with lesser constraints of place or time. This is particularly relevant in the Web 2.0 era. We have shown one example, a networked project, where the conceptualization of a project as a network implies a wider map of relationships by people and institutions.

Policy implications related to fostering and expanding social capital, e.g. via legislation related to the support of volunteer action, should also factor in network capital. Such policies ought to include (i) support to organizations that are already active in creating social capital so they can extend their activities online, (ii) provision of the necessary network infrastructure for social/development purposes, and (iii) research into how network capital is created and how it can be promoted and harnessed in the wider contexts of governance and human development. Ultimately, network capital is a social asset which can appear spontaneously. But as a public good, it will grow better if adequately fostered 
and stimulated, in turn increasing and spreading its benefits. 


\section{Bibliography}

Baym, N. K. (1998). The Emergence of On-Line Community. In: S.G. Jones (ed.) Cybersociety 2.0. Revisiting Computer-Mediated Communication and Community (pg. 35-68). Thousand Oaks, CA : Sage Publications.

Castells, M. (1998). The Rise of the Network Society (The Information Age: Economy, Society, Culture; v.1). Oxford: Blackwell Publishers. 594 p. ISBN 0631221409.

Castells, M. (2001). La Galaxia Internet: Reflexiones sobre Internet, Empresa y Sociedad. Barcelona: Plaza \& Janés. 316 p. ISBN 84-01-34157-4

Gurstein, M. (ed.), (2000). Community Informatics: Enabling Communities with Information and Communications Technologies. Idea Group Publishing; ISBN: 1878289691; 596 p.

Hakken, D. (1999).An Alternative to 'Computer Revolution'Thought.Cyborg@Cyberspace?: An Ethnographer Looks at the Future. NY/London: Routledge.

Jones, S. G. (1998). Information, Internet, and Community: Notes Toward an Understanding of Community in the Information Age. En: S.G. Jones (ed.) (1998). Cybersociety 2.0. Revisiting Computer-Mediated Communication and Community (pp. 1-34). Thousand Oaks, CA: Sage Publications.

Kauchakje, S.; Penna, M. C.; Frey, K.; Duarte, F. (2006). Redes socio-técnicas y participación ciudadana: propuestas conceptuales y analíticas para el uso de las TICs; REDES, 11 (3), December 2006. Retrieved July 19, 2007 from http://revista-redes.rediris.es/html-vol11/Vol11 3.htm\# ftn1

Putnam, R. (1993). Making Democracy Work. Princeton: Princeton University Press. 280 p. ISBN 0691037388 ,

Quan-Haase, A.; Wellman, B.; Witte, J. C.; Hampton, K. N. (2002). Capitalizing on the Net: Social Contact, Civic Engagement, and Sense of Community. In Barry Wellman and Carolyne Haythornthwaite (Eds.) The Internet in Everyday Life. Maryland: Blackwell Publising.

Simpson, L (2005). Community Informatics and Sustainability: Why Social Capital Matters. The Journal of Community Informatics, 1 (2). ISSN: 1712-4441. Retrieved August 3 from http://www.ci-journal.net/index.php/ciej/article/view/210/169.

United Nations Development Programme. (2001). Human Development Report 2001: Making New Technologies Work for Human Development. New York: Oxford University Press. 264 p. ISBN 0-19-521835-3.

United Nations Development Programme. (2002). Capacity for Development: New Solutions to Old Problems. FukudaParr, Sakiko; Lopes, Carlos; Malik, Khalid (eds.). New York: Earthscan Publications. 286 pages. ISBN 185383-919-1

United Nations Volunteers (2000). Below the Waterline of Public Visibility: Roundtable on Volunteerism and Social Development. The Hague, 29-30 November 2000.

Van Bavel, R., Punie, Y., Tuomi, I (2004). ICT-enabled Changes in Social Capital. The IPTS Report 85, July 2004. Retrieved February 3 from http://www.jrc.es/home/report/english/articles/vol85/ict4e856.htm

Wellman, Barry. (2001). Living Networked in a Wired World: The Persistence and Transformation of Community. Report to the Law Commission of Canada, Wellman Associates, Toronto, Canada. (p. 120) 